\title{
Urologic Surgical Procedure
}

National Cancer Institute

\section{Source}

National Cancer Institute. Urologic Surgical Procedure. NCI Thesaurus. Code C15334.

Any surgery performed on any part of the urinary tract or on any part of the male genitalia. 